\title{
TOR PEFERTNE
}

NOT TO EE rAw

\section{Laser Velocimetry in the Low- Speed Wind Tunnels at Ames Research Center}

Kenneth L. Orloff, Philip K. Snyder and Michael S. Reinath

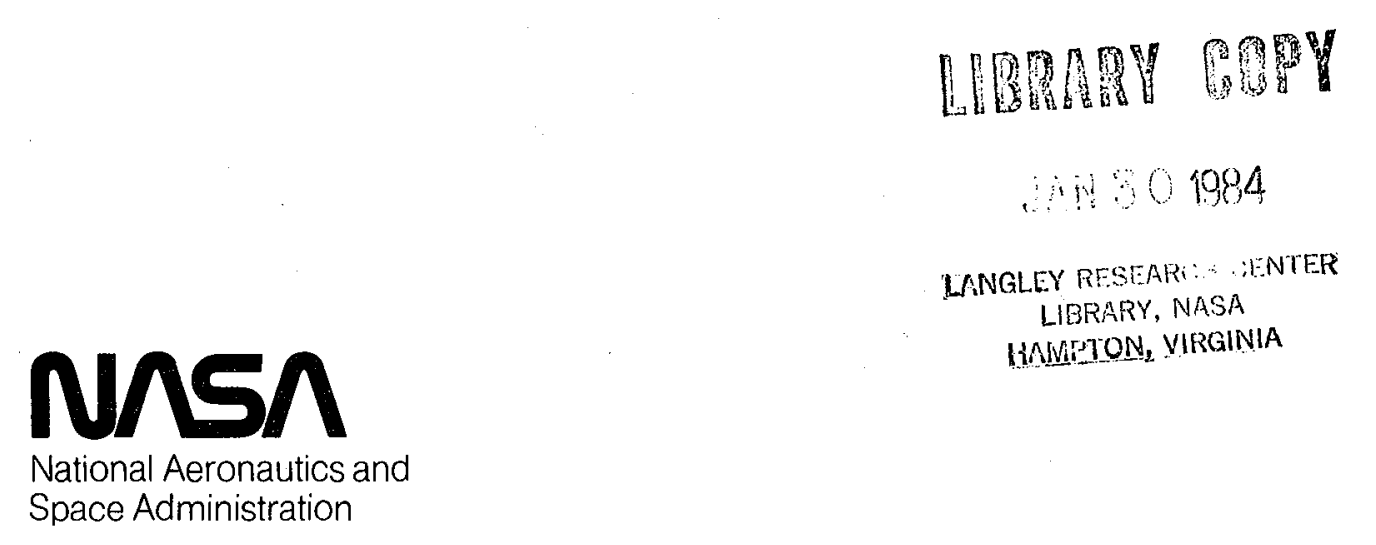




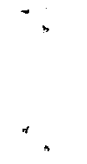


NASA Technical Memorandum 85885

\section{Laser Velocimetry in the Low- Speed Wind Tunnels at Ames Research Center}

Kenneth L. Orloff

Philip K. Snyder

Michael S. Reinath, Ames Research Center, Moffett Field, California 
$\cdot$
$\cdot$.
$\cdot$. 


\section{Abstract}

First, the historical development of laser velocimetry and its application to low-speed (less than $100 \mathrm{~m} / \mathrm{sec}$ ) aerodynamic flows in the subsonic wind tunnels at Ames Research Center is reviewed. Next, a fully three-dimensional velocimeter for the Ames $7-$ by 10-Foot Wind Tunnel is described, and its capabilities are presented through sample data from a recent experiment. Finally, a long-range $(2.6$ to $10 \mathrm{~m})$ velocimeter that is designed to be installed within the test section of the Ames 40- by $80-$ Foot Wind Tunnel is described and sample dat a are presented.

\section{Historical Review}

The development and application of the laser velocimeter (LV) have been important parts of the low-speed aerodynamics research effort at Ames Research Center since 1972 when the first two-color, two-dimensional backscatter laser velocimeter (2DLV) was installed in the Ames 7- by 10-Foot W1nd Tunnel. ${ }^{1}$ The $2 D L V$ simultaneously senses two orthogonal components of the velocity and uses "zoom" optics to translate the focal point along the optical axis. The unit is comparable to the latest two-channel velocimeter systems available today, and it has continued to provide quality data for the last 12 years.

The initial application of the $2 D L V$ was in support of a research effort to alleviate the hazard to small, following alrcraft that is posed by the wake vortices shed from large, transport-type aircraft. First, in the interest of better understanding the basic fluid mechanics of the flow, the $2 D L V$ was used to measure the velocity structure within the vortex generated by a semispan wing. Later, in studies of the effects of flap deployment and landing-gear extension on the coalescence of the vortices, it was used to measure the multiple-vortex wake behind a model of a transport aircraft. Finally, in order to study the decay properties of vortices, the rapid-scanning feature of the $2 \mathrm{DLV}$ was used to measure the decay of vortices formed by towing a wing submerged in a towing basin. ${ }^{4}$

In 1974, laser velocimetry made an important contribution in the field of helfcopter rotor aerodynamics research. By processing LV data over only a short Interval (typically $60 \mathrm{\mu sec}$ ) when the rotor blade is in a specified location relative to the LV test point, and "opening" this "data window" at each successive blade passage, the instantaneous flow around the rotor blade was nonintrusively measured. In 1975 , the $2 D L V$ was integrated with a minicomputer for data acquisition, reduction, and display; position control was also automated by means of a five-motor digital controller that was interfaced to the minicomputer. As a result, rotor inflow measure-

* Research Scientist, member AIAA.

-Research Scientist.

This paper is declared a work of the U.S. Government and therefore is in the public domain. ments were improved significant $1 y$, and the system has since been used extensively to study both the hover ${ }^{5}$ and the forward-f1ight ${ }^{6}$ configurations.

With on-line computer capability, the utflity of the 2DIV was further enhanced in 1977 by combining some basic analytical aerodynamic concepts with the experimental LV velocity measurements in order to extract aerodynamic data in ways that were not previously feastble. Through computerexperiment integration, the $2 \mathrm{DLV}$ was shown to be a valuable tool in accurately measuring spanwise loading distributions on a finite wing without using pressure orifices and pressure transducers. ${ }^{7}$

In 1978, research and development began on a fully three-dimensional laser velocimeter (3DLV). The first application ${ }^{8}$ was in 1981, at which time it was noted that further optimization of the optical system was necessary to yteld a truly useful instrument. Furthermore, the geometric configuration of the system suggested that the effects of systematic and statistical uncertainties should be studied in more detafl; the results of these studies have been reported, 9,10 and operation of the $3 \mathrm{DLV}$ is now much improved and better understood.

Data acquisition, reduction, display, and system control have also been significantly improved. From the first LV application in 1972, with only spectrum analyzers and oscillograph recorders for data acquisition, the system has been developed into one with automated three-channel digital data acquisition and reduction, high-resolution on-line graphics display, user-interactive features for more efficient operation, and computer feedback to the signal conditioning electronics to enhance the LV signal-to-noise ratios. The current status and capabilities of the 3DLV optical system and assoclated electronics, the digital hardware, and the interactive software are presented in the next section of the paper.

A separate research effort in laser velocimetry was begun in 1978 because of a need to make backscatter velocity measurements in the test sections of the Ames 40- by $80-$ foot and the Ames $80-$ by 120-foot wind tunnels. Fabrication and assembly of a laser velocimeter for this purpose began in 1979 and the flrst operational test was made in early 1981 ; after several refinements, accurate laboratory measurements were made and reported ${ }^{11}$ with an intial research application in 1983.12 The details and status of this long-range laser velocimeter (LRLV) are reviewed in the third section of the paper.

\section{Three-Dimensional Laser Velocimeter for the Ames 7- by 10-Foot Wind Tunnel}

The 3DLV optical system shown in Fig. 1 has been optimized for applications in the Ames 7- by 10-Foot Wind Tunnel (subsonic, closed-return). It measures all three velocity components by means of three independent dual-scatter channels that operate in the backscatter direction. As indicated, the two strongest colors $(514.5$ and $488.0 \mathrm{~nm})$ from 
a 4-W argon-ion laser are used for the two channels whose results are together used in a transformation equation that provides the on-axis velocity component, $V$. The 514.5-nm line senses the $W$-component almost directly; the 488.0-nm line senses a combination of the $\mathrm{W}$ - and $\mathrm{V}$-components. The remaining channel utilizes the 476.5-nm 1 ine and is sensitive to the streanwise velocity component, U. All three channels incorporate acoustooptic cells for frequency offset to provide flow-directional sensitivity. A combination of mechanical tilt and variable focusing (both digitally controlled) are used to ensure that the focal point of the upper (off-axis) channel remains colocated with the focal point of the lower (2D) portion as the lower (2D) optics "zoom" across the test section. These motfons implement lateral positioning of the test point within the test section; vertical and streamwise motion are accomplished by moving the entire package on a digitally controlled platform. The repeatable positioning accuracy is better than $0.5 \mathrm{~mm}$; the spatial resolution (probe-volume size) is of the order of $1.5 \mathrm{~mm}$.

Because the $3 \mathrm{DLV}$ involves nonlinear positioning of five stepping motors, data transfer from three signal processors, and communication with several other devices, the velocimeter optics and electronics are interfaced to a dedicated high-speed minicomputer with extensive pertpheral and I/O capability, as indicated in Fig. 2. The computer automatically performs test-point positioning and path control through communication with five steppingmotor controllers. Optical encoder readback to the controllers ensures location accuracy.

The system software is destgned to be highly interactive so that the sctentist can most effectively use the $3 \mathrm{DLV}$ for aerodynamics research. To accomplish this, spectal data-acquisition, reduction, and display methods have been incorporated to ensure that the data taken are of good quality. For example, during data acquisition, the main graphics display is used to plot reduced data as a function of location as the LV test point moves along a userprescribed path in the flow. At the same time, the computer analyzes the incoming data and displays histograms and sample statistics (on the graphics terminal for any selected LV channel) so that the scientist has immediate feedback about data quality and can make adjustments as required. When surveys are completed, the results on the main graphics display can be transferred to a pen plotter.

Unfortunately, backscatter velocimeters are subject to an inherently poorer signal-to-noise ratio (SNR) than is characteristic of forwardscatter velocimeters. Because the SNR is inversely proportional to the processing bandwidth, it follows that the SNR can be enhanced by minimlaing the bandwidth. On the other hand, if the bandwidth is too narrow, the incoming data may be biased by the filter bandpass if 1 ) the mean frequency moves to the edges of the bandpass as the mean velocity varies during a flow survey, or 2) the turbulence intensity is high enough to cause the distribution of frequencies to overshoot one or both edges of the bandpass. To alleviate this problem, the 3DLV system incorporates state-of-the-art, programable frequency synthesizers that generate, for each channel, a mixer frequency that can be varied under program control so as to maintain the mean signal frequency (as seen by the processor) at the center of the bandwidth. In this way, the SNR is improved because a minimum bandwidth may be used. Also, at a constant signal frequency, the signal processor accuracy remains constant.

A microcomputer acts as a slaved dataacquisition and buffer unit. It acquires data samples as instructed by the minicomputer and sends an interrupt when it is ready to transfer a batch of data. During the time that the microcomputer is acquiring data from the IV processors, the minicomputer carries out diagnostics on the previous data set that was transferred and presents the information on the graphics terminal display.

The authors have previously reported ${ }^{10}$ a generalized error analysts for an arbitrary $3 \mathrm{DLV}$ geometrical arrangement. The analysis involves the use of a transformation matrix, $A_{i j}$, that when multiplied by the three measured mean frequencies, yields the orthogonal components of the velocity according to

$$
\left(\begin{array}{l}
U \\
V \\
W
\end{array}\right)=\left(\begin{array}{lll}
A_{11} & A_{12} & A_{13} \\
A_{21} & A_{22} & A_{23} \\
A_{31} & A_{32} & A_{33}
\end{array}\right)\left(\begin{array}{l}
f_{1} \\
f_{2} \\
f_{3}
\end{array}\right)
$$

The geometrical detalls of the velocimeter and other constants are contained in the matrlx $A_{1 j}$. For the $3 D L V$, the small coupling angle (nominally $17^{\circ}$ ) between the on-axis and off-axis channels places stringent requirements on the accuracy to which the elements $A_{1 j}$ must be determined. A special calibration technique that reduces systematic errors in the measurement of these elements to acceptable levels has been developed and a patent has been applied for. ${ }^{13}$

The effects of statistical uncertainty on the accuracy of the 3DLV have been extensively studied ${ }^{10}$ and can be summarized in the following equations:

$$
\begin{aligned}
\Delta V_{1} & =\frac{z_{c}}{N^{1 / 2}} \sum_{j=1}^{3}\left(A_{i j} s_{j}\right)^{2} \\
\Delta \theta & =\frac{z_{C}}{V_{Y Z^{N}} N^{1 / 2}} \sum_{j=1}^{3}\left(A_{2 j} \cos \theta-A_{3 j} \sin \theta\right) s_{j}^{2}
\end{aligned}
$$

where $\Delta v_{1}$ is the confidence interval for the velocity component $V_{i}(U, V$, or $W) ; z_{c}$ is the confidence coefficient for Gaussian statistics; $s_{j}^{2}$ is the variance in the distribution of frequency for the $j$ th $(j=1,2,3) \mathrm{LV}$ channel for which the measured mean frequency is $f_{j}$; and $N$ is the size of the ensemble for which the sample statistics are computed (1.e., the number of velocity samples taken from each LV channel). When the measured velocity vector is projected into the YZ plane, the projection, $V_{Y Z}$, is at an angle $\theta$ measured from the $Y$-axis; and $\Delta \theta$ is the confidence interval on $\theta$. Simflar expressions can be generated for the angles obtained by projecting the velocity vector into the $X Y$ and $Z X$ planes.

The theory assocfated with Eqs. (2) and (3) has been incorporated into the data-acquisition software for the $3 D L V$ and, in effect, it defines the system operating procedures. For example, before a 
velocity survey begins, the software prompts the user to spectfy the desired error criterion; the user enters whether it is to be "velocity component" or "flow direction" and specifies the maximum acceptable error $\left(\Delta V_{1}\right.$ or $\left.\Delta \theta\right)$ for the survey. As the survey proceeds automatically, the computer varies the number of samples. $N$ collected at each location in order to maintain the specifted accuracy as the local flow conditions (turbulence and vector direction) change.

As an example of a typical research application of the 3DLV, the instrumentation has been used to measure the flow associated with a $5-\mathrm{cm}-\mathrm{diam}$ cold jet issuing normally from a surface plate (ground plane) Into the wind-tunnel crossflow. The research was conducted in confunction with V/STOL basic aerodynamics research. Figure 3 illustrates the installation of the $3 \mathrm{DLV}$ relative to the wind tunnel and the jet; the $3 D L V$ is tilted $2.74^{\circ}$ to allow measurements to be made closer to the surface. The jet velocity was $V_{\text {jet }}=85 \mathrm{~m} / \mathrm{sec}$ and the velocity ratio was $v_{j e t} / v_{\infty}=8$. The main features of the flow are sketched in Fig. 4. Of particular interest to flufd dynamicists who have modeled the flow is the detalled velocity structure around the $j$ et exit and in 1ts wake. To provide such data, comprehensive measurements were made in horizontal and vertical planes (FIg. 4). Whereas all three velocity components are measured and stored for each point, the horfzontal-plane data require only the $U$ and $\nabla$ velocity components, and the vertical-plane data require only the $\mathrm{V}$ and $W$ velocity components.

Figure 5 is a top view of the measured velocity vectors profected into the horizontal plane indicated in Fig. 4; it is a compilation of surveys made in the $Y$-direction (parallel to the ground plane) for several $x$-locations in the vicinity of the jet exit. The acquisition criterion for these data was that the $95 \%$-confidence interval for the $V$-component of velocity be between 0.5 and $1.0 \mathrm{~m} / \mathrm{sec}$, depending on the survey. Because of the two-channel coupling involved in obcaining $V, \Delta U$ and $\Delta W$ are approximately 5 times smaller than $\Delta V$ (for the same number of samples, $N$ ) for the geometrical configuration of the 3DLV; hence, it is generally $\Delta V$ that is specified for a survey as the main limitation to accuracy. Also, note that the turbulence intensity varies considerably with location; this results in correspondingly large variations in the number of samples required by Eq. (2). In this study, the number of samples typically varied from 200 in regions of low turbulence to as high as 3,000 in regions of high turbulence. The figure clearly shows the effect of entrainment in the wake region of the jet. The details of the inflow and entrainment are even clearer when the surveys labeled $A$ and $B$ in Fig. 5 are viewed looking upstream, as presented in Fig. 6 .

The induced-velocity fleld of the weak surface vortices shown in Fig. 4 (as they pass through a vertical data-plane) can be visualized quantitatively, as shown in Fig. 7. Again, the surveys that comprise the vector display utilize the indirectly measured $V$-component of velocity. Notlce that by taking the correct number of samples, $N$, the 3DLV system can accurately measure even small values of the mean velocity in the presence of high turbulence.

Finally, Eq. (3) Indicates that the local flow direction can be measured to within a prescribed confidence interval. Accordingly, a new technique has been developed ${ }^{14}$ wherein the $3 \mathrm{DLV}$ test point is moved within' the flow in such a way that it follows along a mean streamline. Path control requires an involved three-dimensional algortthm that suppresses cumulative path errors and corrects for local flow curvature and inflection. The resulting path is displayed by the computer graphics as the motion takes place. Any two planes may be selected by the user for viewing the streamline. Using a criterion that the flow direction have a $95 \%$-confidence interval of $10^{\circ}$, the streamline traces presented in Fig. 8 were obtained as on-line displays during the jet-in-a-cross-flow application of the 3DLV. Each of the streamlines were begun at $5 \mathrm{~cm}$ above the surface plate and at various $Y$-values about the centerline, as Indicated. For clarity, only the traces labeled A through $D$ in the $X Y$ plane are shown in the $\mathrm{zx}$ plane.

\section{Long-Range Laser Velocimetry}

Laser velocimetry in small wind-tunnel factiities and in laboratory environments has become routine, but its implementation for research purposes in large wind tunnels and at extended ranges has been quite limited. In smaller wind tunnels, optical windows can easily be installed so that the LV can be positioned outside of the test section; in large wind tunnels, however, the window Installation allows only limited access to the test section, and the range requirements to measure beyond the wind-tunnel centerline may be excessive.

Figure 9 is a schematic representation of how a long-range laser veloctmeter (LRLV) wlll be installed in the Ames 40- by 80-Foot Wind Tunnel. The entire streamlined optical package ( $4.3 \mathrm{~m}$ in length, $0.76 \mathrm{~m}$ in diameter) is mounted within the test section on lateral rails that are located at a selected longltudinal position (the addition of longltudinal motion is achieved by repositioning the rail system, which is only temporartly attached to the tunnel floor). Test-point positioning is accomplished through a combination of lateral motion along the ralls, mechantcal rotation of the entire upper tubular section, and variable focusing by means of zoom optics within the package. The LRLV can be positioned to within $0.025 \mathrm{~cm}$ along the lateral rails, which are 6 m long; the rotation capability is $45^{\circ}$ to either side of the vertical or the horizontal (depending on how the detachable folding-mirror/output-window assembly is installed) with a resolution of 0.2 mrad. Optical focusing can position the test point over a range of 2.6 to $10 \mathrm{~m}$, with a nominal accuracy of $0.2 \mathrm{~cm}$. A computer-controlled stepper motor with absolute optical encoder read-back is used for each of the scanning motions. With minor changes, the optical range can be extended for use in the Ames $80-$ by 120-Foot Wind Tunnel, as well as in the Ames Outdoor Aerodynamic Research Fac1lity.

The basic components of the LRLV are shown in Fig. 10. The instrument is a single-color, dualbeam backscatter device that utilizes special beamsplitting and frequency-shifting techniques that must withstand the energy density of the high-power laser beam from an $18-W$ argon-ion laser that is capable of producing $9 \mathrm{~W}$ of single-color output. Using a patented ${ }^{15}$ beam-rotation assembly, two orthogonal components of the velocity can be measured; one measured component is always in the streamwise direction. 
Contained within the LRLV is an on-board microprocessor controller and digital motor-control hardware. As 1llustrated in Fig. 11, the unit is connected through a communications cable (that may be as long as $60 \mathrm{~m}$ ) to $\mathrm{LV}$ signal-processing electronics and a controller interface located in the windtunnel control room. The controller interface, as instructed by a microcomputer, is used to transfer motion and beam-rotation commands to the on-board microprocessor; it also recelves and buffers the data from the LV signal processor and transfers data to the microcomputer, under program control.

The controller interface can be used with or without the microcomputer. In 1ts "stand-alone" mode it can be used to manually position the LRLV. In either mode, the interface displays test-point position in wind-tunnel coordinates, and it selectively reduces the incoming signal-processor data and displays the measured velocity component in meters per second. Thus, the interface is useroriented, and greatly simplifies implementation of the LRLV for routcine wind tunnel testing.

The LRLV system has not yet been applied within the wind-tunnel test section. Nevertheless, 1ts range capabilities have proved quite useful for other related studies. As an example of a typical research application of the LRLV, Fig. 12 presents vertical surveys made through the exhaust flow of a 1/50-scale model of the Ames 80- by 120-Foot Wind Tunnel. At each streamwise location, surveys were accomplished by package rotation and by optical scanning to distances in excess of $7 \mathrm{~m}$. Using the beam-rotation feature of the LRLV, direct measurements were made of two orthogonal velocity components at each location along the survey lines. The horizontal velocity component (parallel to the ground) was obtained directly and the vertical component was obtained by making a small cosine correction to the tilted measurement; it was verffied that no significant lateral flow was present in the survey plane. These data clearly document the magnicude of the exhaust flow, as well as its decay properties for vartous deflector ramps that have been studied.

\section{Concluding Remarks}

Laser velocimetry in the low-speed wind tunnels at Ames Research Center has proved to be a valuable complement to conventional wind-tunnel instrumentation. The velocimeters described in this paper have been improved using state-of-the-art optical techniques, signal processing electronics, automatic control equipment, minicomputers, and computer peripherals.

In particular, the use of programmable frequency sources to control the mean IV signal frequency, as described for the 3DLV, greatly improves the ultimate quality of the data. Moreover, because the technique reduces the possibility of bandwidth overrun, the utility of the 3DLV system for general wind-tunnel applications is enhanced, and the research and development nature of the velocimeter itself is decreased. This approach to improvement will continue to be applied to both the 3DLV and the LRLV.

Applications techniques have also been shown to play a significant role in the utility of a laser velocimeter. For the 3DLV, incorporation of a statistical analysis into the system software has proved to be essential for quality data. Also, the successful, new technique of streamline tracing suggests that the fluid dynamics of complex aerodynamic flow flelds can now be studied in ways that were heretofore not feasible.

The LRIV will be a valuable asset for the large wind tunnels at Ames Research Center. New optical techniques and special methods for remote operation have been developed and have proved highly successful. With this instrument, a permanent installation is now possible for velocity measurements within the test section. Furthermore, the installation is model-independent and eliminates the need for large probe-support structures, which can cause flow disturbances near the model. For example, tall-off downwash and profile-drag measurements can now be made without the need for wake pitot-static rakes, and spanwise loading distributions can be determined without the need for pressure taps on the model.

\section{References}

IGrant, G. R. and Orloff, K. L., "Two-Color Dual-Beam Backscatter Laser Doppler Velocimeter," Applied Optics, Vol. 12, Dec. 1973, pp. 2913-2916.

${ }^{2}$ orloff, K. L., "Tralling Vortex Wind-Tunnel Diagnostics with a Laser Velocimeter," Journal of Aircraft, Vol. 11, No. 8, Aug. 1974, pp. 477-482.

${ }^{3}$ Corsiglla, V. R. and Orloff, K. L., "Scanning Laser-Velocimeter Surveys and Analysis of Multiple Vortex Wakes of an Aircraft," NASA TM X-73,169, 1976.

${ }^{4}$ Ciffone, D. L. and Orloff, K. L., "Far-Field Wake-Vortex Characteristics of Wings," Journal of Aircraft, Vo1. 12, No. 5, May 1975, pp. 464-470.

${ }^{5}$ Ballard, J, D., Orloff, K. L., and Luebs, A. B., "Effect of Tip Planform on Blade Loading Characteristics for a Two-Bladed Rotor in Hover," NASA TM-78,615, 1979 .

${ }^{6}$ Biggers, J. C., Lee, A., and Orloff, K. L., "Laser Velocimeter Measurements of Two-Bladed Helicopter Rotor Flow Flelds," NASA TM-73,238, 1977.

${ }^{7}$ Orloff, K. L., "Spanwise Lift Distribution on a Wing from Flowfield Velocity Surveys," Journal of Alrcraft, Vo1. 17, No. 12, Dec. 1980, pp. 875-882.

${ }^{8}$ Snyder, P. K., Orloff, K. L., and Aoyagi, K., "Performance and Analysis of a Three-Dimensional Nonorthogonal Laser Doppler Anemometer," NASA TM-81,283, 1981 .

${ }^{9}$ Orloff, K. L. and Snyder, P. K., "Laser Doppler Anemometer Measurements Using Nonorthogonal Velocity Components: Error Estimates," Applied Optics, Vol. 21, Jan. 1982, PP. 339-344.

${ }^{10}$ Snyder, P. K., Orloff, K. L., and Reinath, M. S., "Reduction of Flow-Measurement Uncertainties in Laser Velocimeters with Nonorthogonal Channels," AIAA Paper 83-0051, Reno, Nev., 1983.

${ }^{11}$ Reinath, M. S., "Laser Velocimeter for Large Wind Tunnels," Journal of Aircraft, Vo1. 19, No. 12,. Dec. 1982, pp. 1100-1102. 
${ }^{12}$ Reinath, M. S., Orloff, K. L., and Snyder, P. K., "A Laser Velocimeter System for the Ames $40-$ by $80-$ Foot and $80-$ by 120 -Foot Wind Tunnels," AIAA Paper 84-0414, Reno, Nev., 1983.

${ }^{13}$ Snyder, P. K., "Spinning Disk Calibration Device for Laser Doppler Anemometers," patent pending, 1983 .
${ }^{14}$ Orloff, K. L. and Snyder, P. K., "An Algorithm for Using a Laser Anemometer to Determine Mean Streamline Patterns in a Turbulent Flow," NASA TM-84,340, 1983 .

${ }^{15}$ Orloff, R. L., "Rhomboid Prism Pair for Rotating the Plane of Parallel Light Beams," U.S. Patent $4,355,870$, Oct. 1982 .

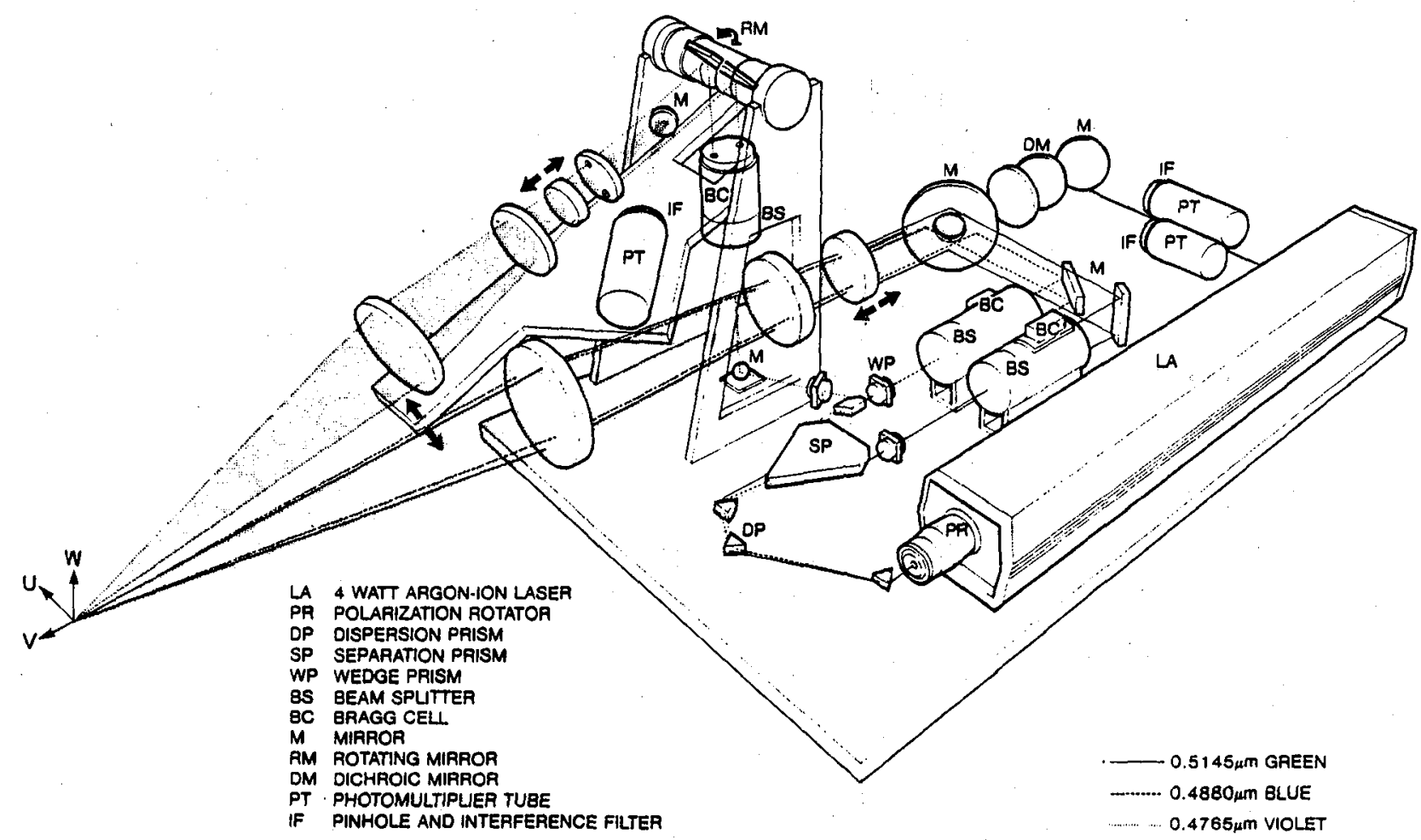

Fig. 1 Three-dimensional laser velocimeter (3DLV) uses three different colors from a single argon-ion laser to form three independent dual-scatter backscatter channels. 


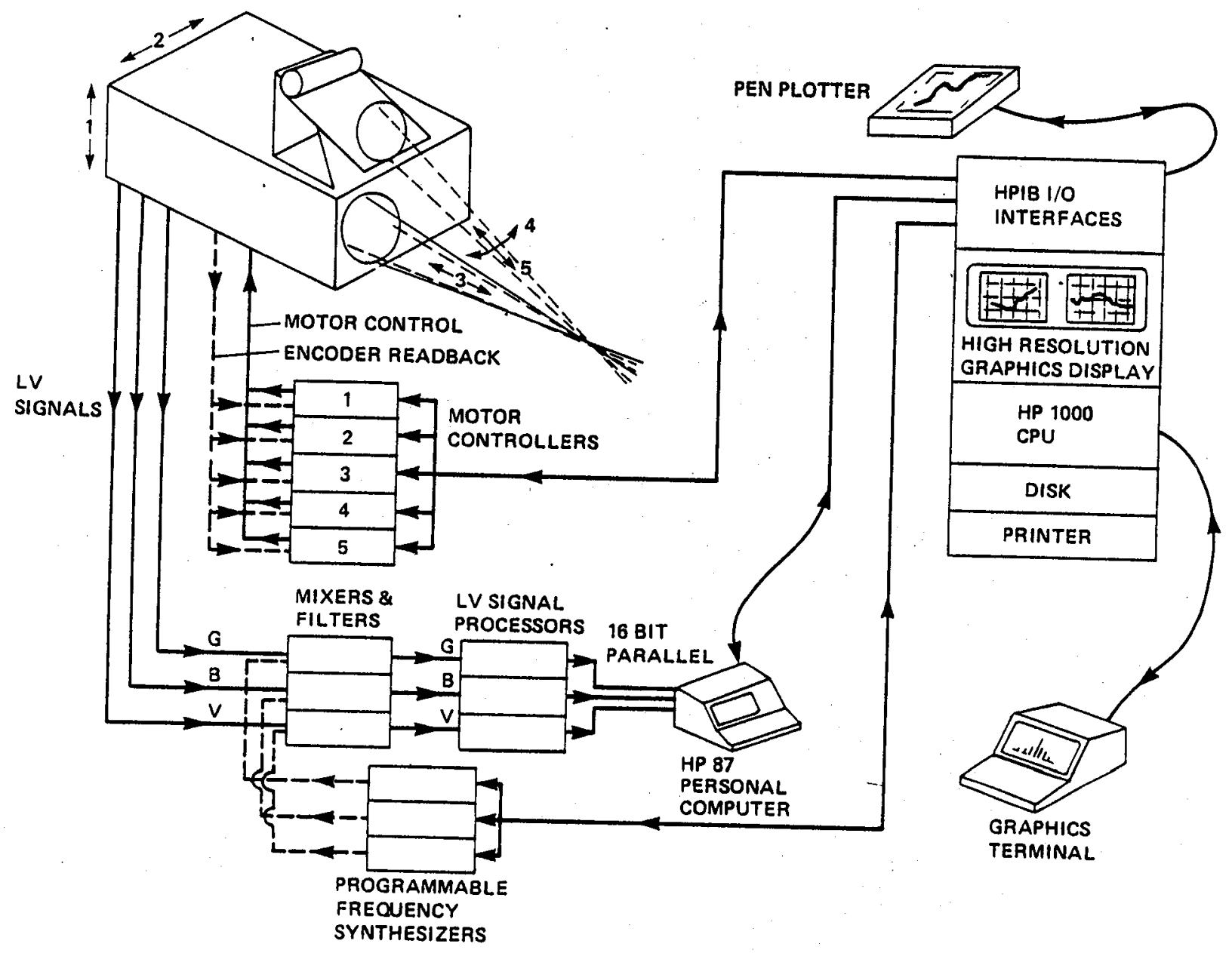

Fig. 2 3DLV minicomputer-based data acquisition, reduction, display, and control system. 


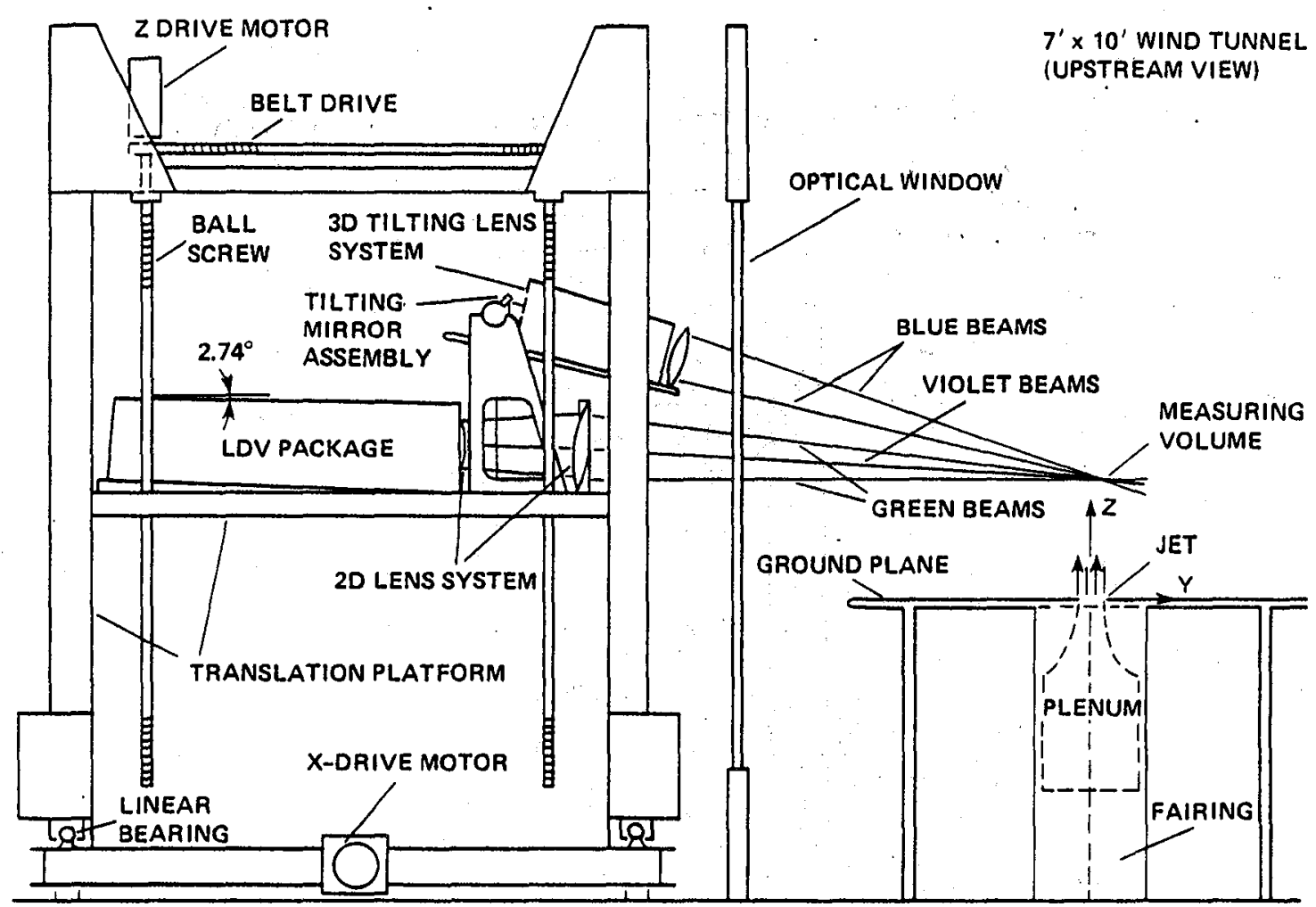

Ffg. 3 3DLV translation platform and wind tunnel installation for jet-in-a-crossflow application.

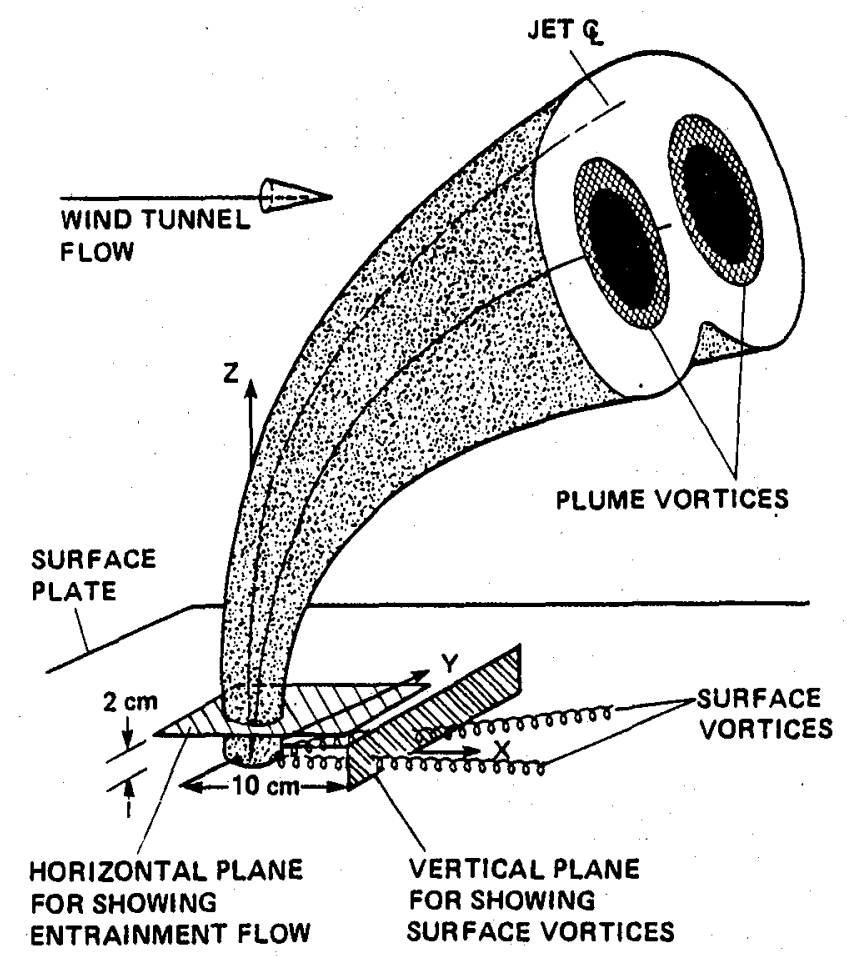

Fig. 4 General features of flow generated by a jet in a crossflow showing planes for presentation of 3DLV data. 


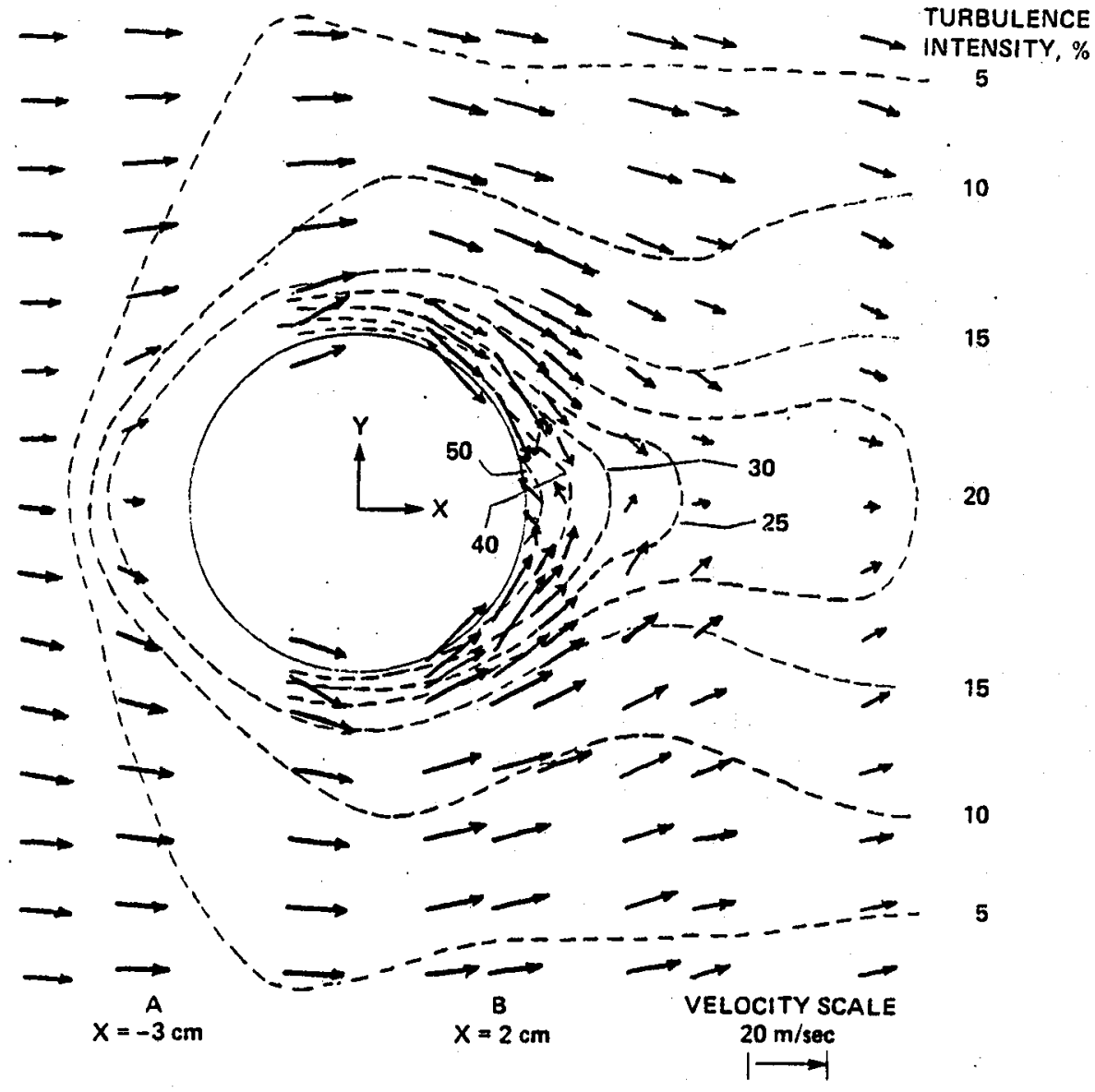

Fig. 5 Top view of horizontal plane noted in Fig. 4; measured mean velocity projections in the $X Y$ plane showing entrainment effect in wake region.

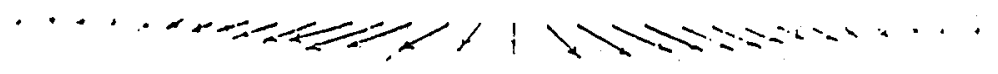
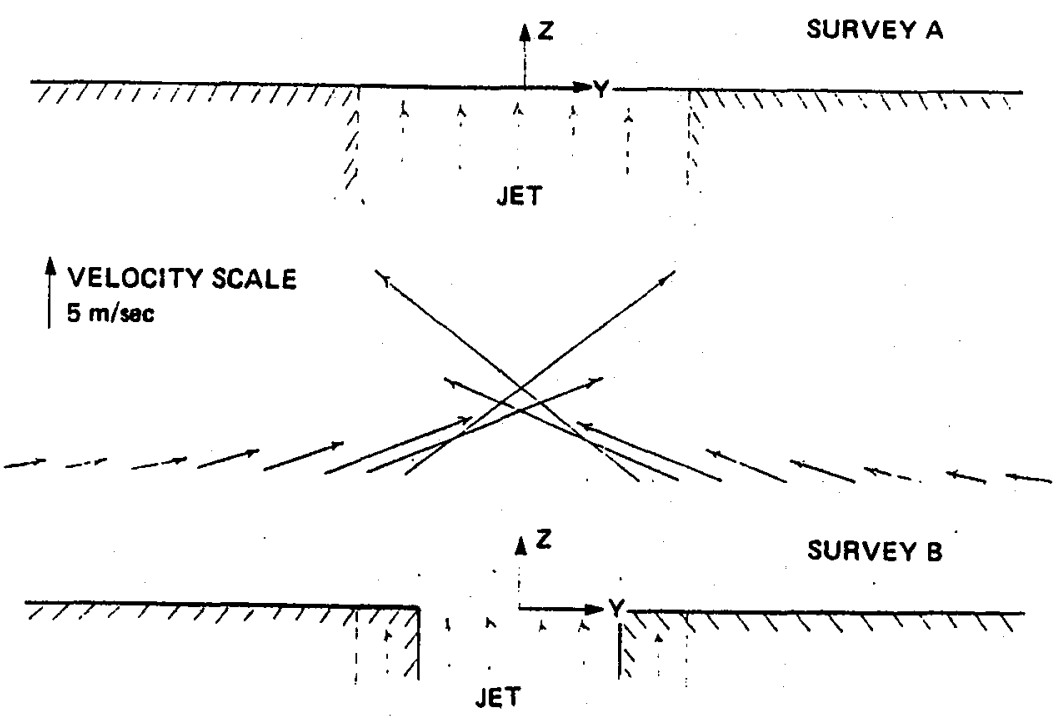

Fig. 6 Measured mean velocity projections in the YZ plane; view looking upstream for surveys $A$ and $B$ noted in Fig. 5 . 


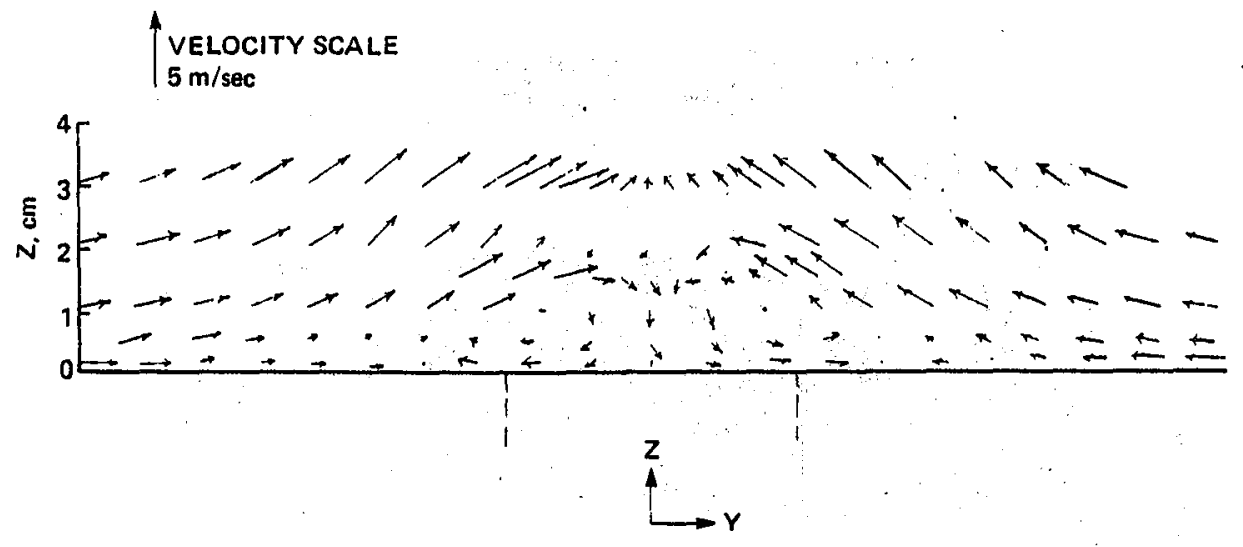

Fig. 7 View looking upstream into vertical plane indicated in Fig. 4 showing surface vortices near the ground plane.
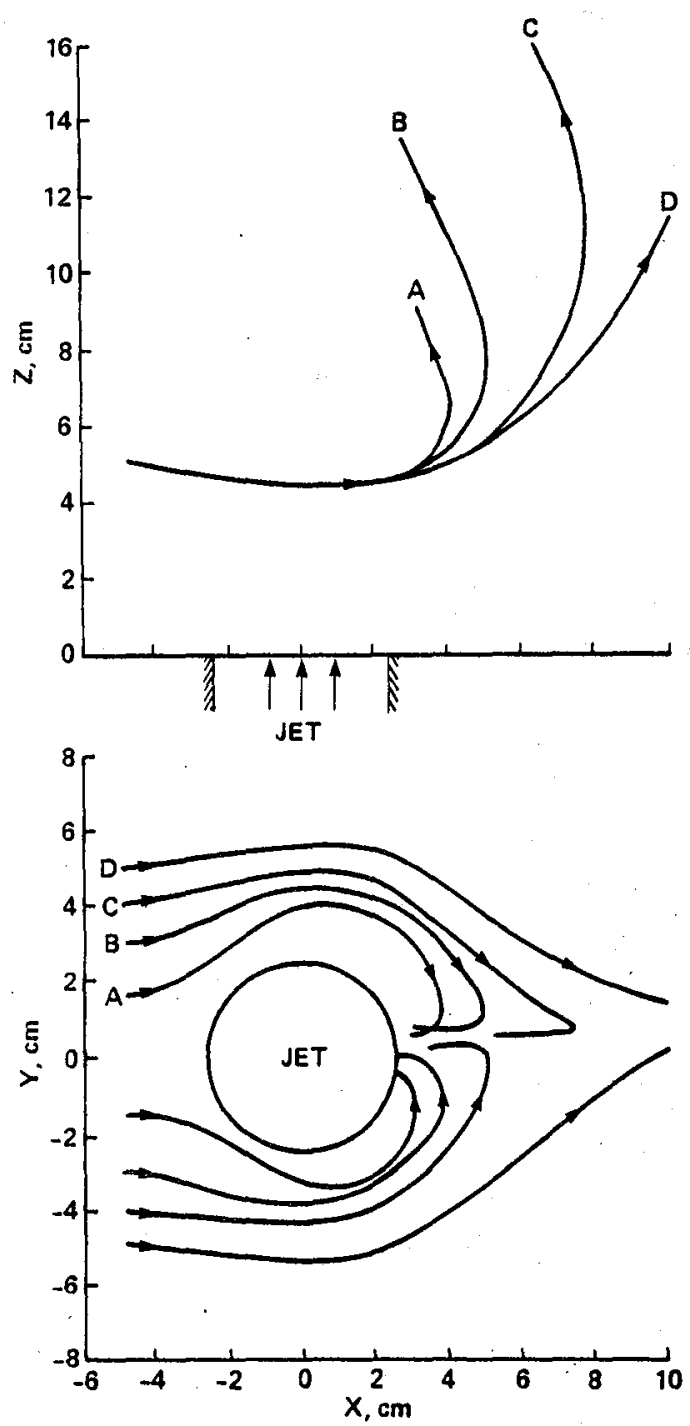

Fig. 8 3DLV streamline traces showing side and top views; traces represent $95 \%$ confidence that angular accuracy at each location along a trace is within $10^{\circ}$.

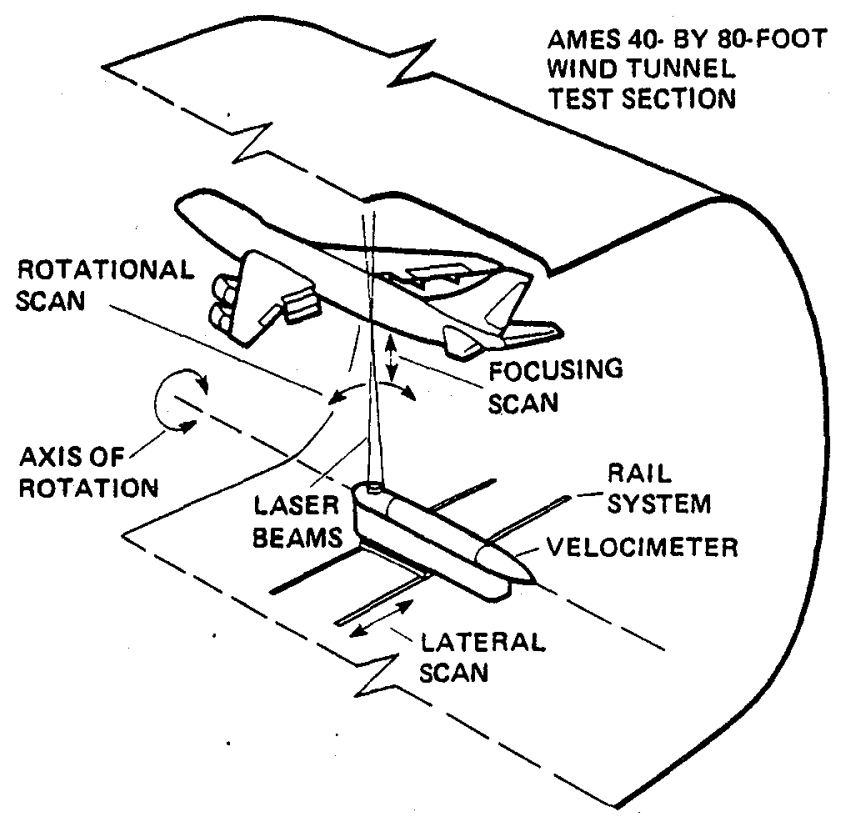

Fig. 9 Installation schematic showing test-point positioning features of the long-range laser velocimeter. 


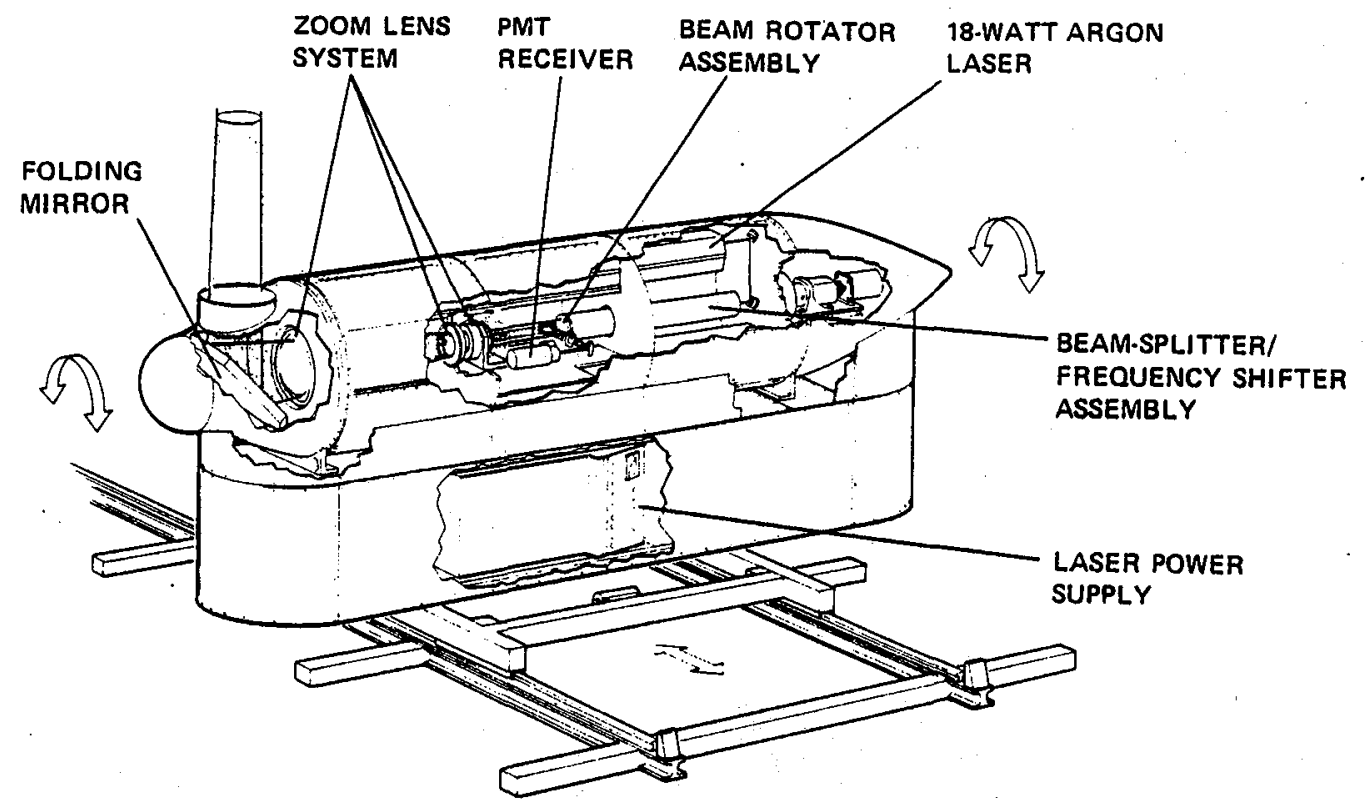

Fig. 10 Major components of the long-range laser velocimeter.

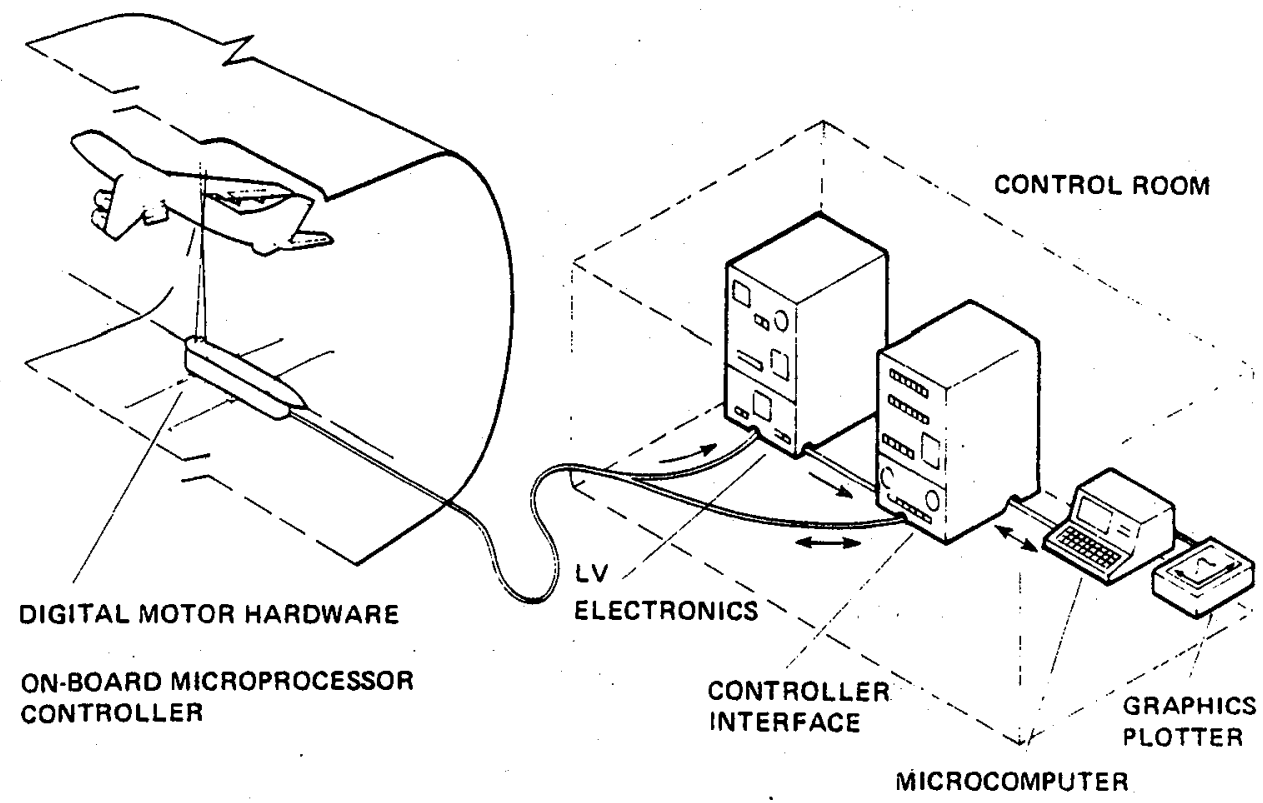

Fig. Il Long-range laser velocimeter data acquisition, display, and control system. 


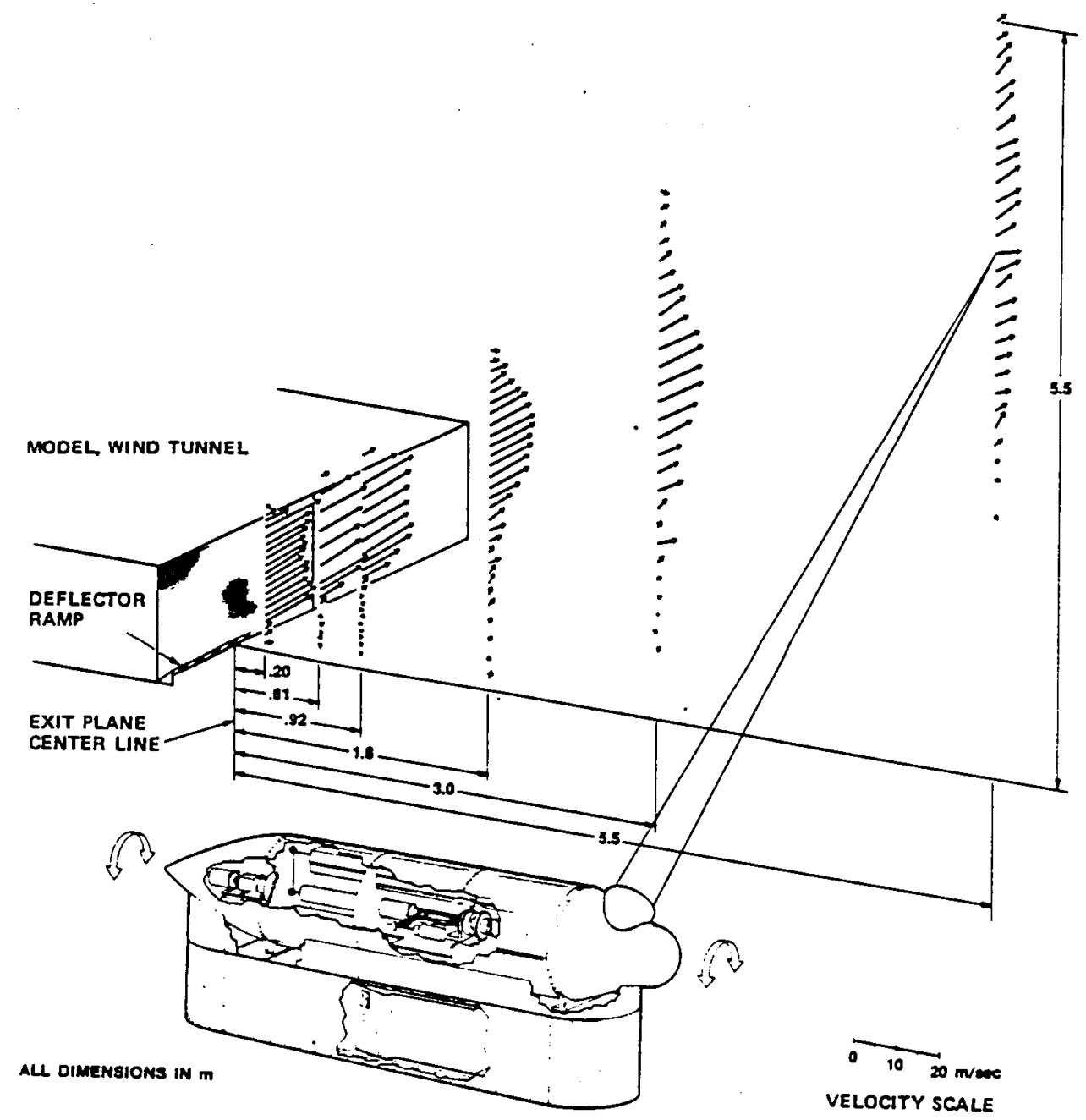

Fig. 12 LRLV measurements of exhaust flow of 1/50-scale model of Ames 80- by 120-Foot Wind Tunnel. All dimensions are in meters. 


\begin{tabular}{|c|c|c|c|}
\hline $\begin{array}{l}\text { 1. Report No. } \\
\text { NASA TM } 85885\end{array}$ & 2. Government Accession No. & \multicolumn{2}{|c|}{ 3. Recipient's Catalog No. } \\
\hline \multicolumn{2}{|c|}{$\begin{array}{l}\text { 4. ritle and Subtitle } \\
\text { Laser Velocimetry in the Low-Speed Wind Tunnels at } \\
\text { Ames Research Center }\end{array}$} & \multicolumn{2}{|c|}{$\begin{array}{l}\text { 5. Report Date } \\
\text { Jamwaxy } 1984\end{array}$} \\
\hline \multicolumn{2}{|c|}{$\begin{array}{l}\text { Rennorkh L. Orloff, Philip K. Snyder and } \\
\text { Michael S. Reinath }\end{array}$} & \multicolumn{2}{|c|}{$\begin{array}{l}\text { 8. Performing Organization Report No. } \\
\text { A } 9620\end{array}$} \\
\hline \multirow{2}{*}{\multicolumn{2}{|c|}{$\begin{array}{l}\text { 9. Performing Organization Name and Address NASA } \\
\text { Ames Research Center, Moffett Field, Californi }\end{array}$}} & \multicolumn{2}{|c|}{$\begin{array}{l}\text { 10. Work Unit No. } \\
\text { T } 3430\end{array}$} \\
\hline & & \multicolumn{2}{|c|}{ 11. Contract or Grant No. } \\
\hline \multicolumn{2}{|c|}{$\begin{array}{l}\text { 12. Sponsoring Agency Name and Address } \\
\text { Nationa1 Aeronautics and Space Administration } \\
\text { Washington, D. C. } 20546\end{array}$} & \multicolumn{2}{|c|}{$\begin{array}{l}\text { 14. Sponsoring Agency Code } \\
505-31-51\end{array}$} \\
\hline \multicolumn{4}{|c|}{$\begin{array}{l}\text { 15. Supplementary Notes } \\
\text { Point of contact: Kenneth L. Orloff, Ames Research Center, MS 247-1, } \\
\text { Moffett Field, CA. (415) } 965-5033 \text { or FTS } 448-5033\end{array}$} \\
\hline \multicolumn{4}{|c|}{$\begin{array}{l}\text { 16. Abstract } \\
\text { First, the historical development of laser velocimetry and its applica- } \\
\text { tion to low-speed (less than } 100 \mathrm{~m} / \mathrm{sec} \text { ) aerodynamic flows in the subsonic } \\
\text { wind tunnels at Ames Research Center is reviewed. Next, a fully three- } \\
\text { dimensional velocimeter for the Ames } 7-\text { by } 10-\text { Foot Wind Tunnel is described, } \\
\text { and its capabilities are presented through sample data from a recent } \\
\text { experiment. Finally, a long-range }(2.6 \text { to } 10 \mathrm{~m} \text { ) velocimeter that is designed } \\
\text { to be installed within the test section of the Ames } 40-\text { by } 80-\text { Foot Wind } \\
\text { Tunnel is described and sample data are presented. }\end{array}$} \\
\hline \multicolumn{4}{|c|}{\begin{tabular}{l|l} 
17. Key Words (Suggested by Author(s)) & 18. Distribution Statement \\
Lasers & Un1imited \\
Velocity measurement & \\
Wind tunnel instrumentation &
\end{tabular}} \\
\hline $\begin{array}{l}\text { 19. Security Classif. (of this report) } \\
\text { Unc1 }\end{array}$ & $\begin{array}{l}\text { 20. Security Classif. (of this page) } \\
\text { Uncl }\end{array}$ & $\begin{array}{l}\text { 21. No. of Pages } \\
14\end{array}$ & $\begin{array}{l}\text { 22. Price* } \\
\mathrm{AO} 2\end{array}$ \\
\hline
\end{tabular}

"For sale by the National Technical Information Service, Springfield, Virginia 22161 

